\title{
Surviving Civilization: Rereading the History of Taiwan and Modernity
}

Wu He, Les Survivants (The Survivors), trans. Esther Lin-Rosolato and Emmanuelle Péchenart, Arles, Actes Sud, 2011, 300 pp.

\section{Sebastian Veg}

\section{(2) OpenEdition}

\section{Journals}

Electronic version

URL: http://journals.openedition.org/chinaperspectives/5831

DOI: 10.4000/chinaperspectives.5831

ISSN: 1996-4617

\section{Publisher}

Centre d'étude français sur la Chine contemporaine

\section{Printed version}

Date of publication: 30 March 2012

Number of pages: 69-72

ISSN: 2070-3449

\section{Electronic reference}

Sebastian Veg, "Surviving Civilization: Rereading the History of Taiwan and Modernity », China Perspectives [Online], 2012/1 | 2012, Online since 30 March 2012, connection on 21 September 2020. URL : http://journals.openedition.org/chinaperspectives/5831 ; DOI : https://doi.org/10.4000/ chinaperspectives.5831 


\section{Surviving Civilization:}

\section{Rereading the History of Taiwan}

\section{and Modernity}

SEBASTIAN VEG*

$\mathrm{T}$

he novel Yu sheng 餘生 by Wu He 舞鶴 (Dancing Crane, the pen-name used by Ch'en Kuo-ch'eng 陳國城), first published in 1999 in Taiwan, has become something of a literary myth in certain circles, the work of a writer showered with prizes in the 1990s after re-emerging from ten years of reclusion in Tamsui. Born in Chiayi in 1951, Wu He lost his mother at 18 and began studying engineering at Cheng Kung University before transferring to the Chinese department in 1973. He was revealed to the literary scene with the publication of his first novella "Peony Autumn" (Mudan qiu 牡丹秋, included in the collection Sadness/Beishang 悲傷 ). He then became strongly involved in the literary journals associated with the Taiwanese "modernist" movement, in particular the "Avant-garde" series (Qianwei congkan). After having belatedly served out his military duties in 1979-1981, he lived in reclusion during his "ten years in Tamsui," during which he wrote several other novellas, including "The Two Deserters" ( Taobing er ge 逃兵二哥; also included in Sadness), which were only published after his "return to the world." When he moved back to the south of Taiwan in 1991 , he notes that he seriously considered a final retreat to a Buddhist monastery before deciding that he could not renounce literature. (1)

The translators have therefore done francophone readers a great favour by giving them access to the first foreign translation of a cult text, the fruit of many years of reflection by the author on Taiwanese culture, and of two "fieldwork" trips to an aboriginal village during the winters of 1997 and 1998. This text probably presented some very significant difficulties to the translators: written as a single paragraph of more than 200 pages in the original, divided into a little more than 20 sentences separated by full stops, written in a mixture of the precise and analytical Chinese used by the narrator and the more oral style reflecting the "non-standard" language used by the "mountain" aboriginals in the area around Puli (near the centre of the island), it is not always an easy read. On the whole, however, the translation is successful in rendering both the letter and the tone of the original text, including the creative coining of new words. (2)

It is not easy to provide a simple characterisation of the narrative created by Wu He. On one level, it is an investigation of

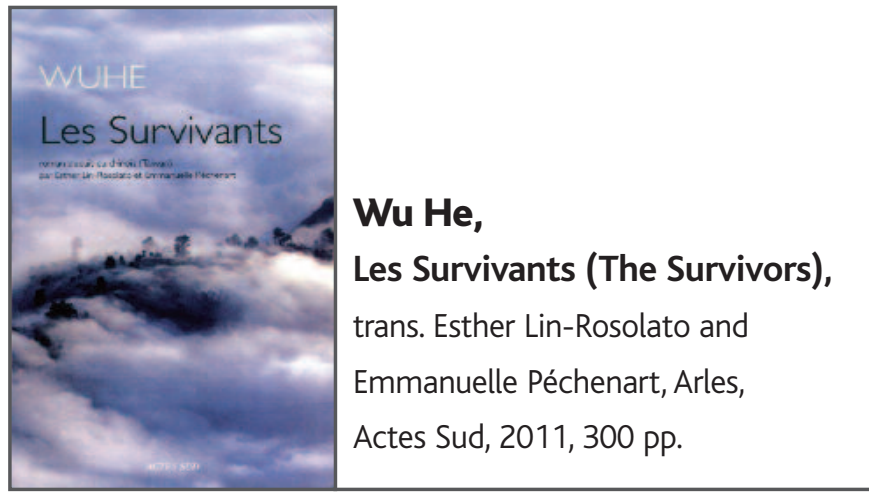

the memory of the Musha Incident (Japanese transcription; Wushe 霧社 in Mandarin), the massacre of more than 100 Japanese colonisers by the Sedeq aboriginals led by Mona Rudao (1882-1930) on a sports field in 1930, followed by terrible retaliation by the Japanese colonial authorities, who resorted to aerial bombing and the use of toxic gas. The remaining Sedeq (many had committed mass suicide) were interned in camps. The Japanese also instigated a retaliatory massacre by another tribe, the Tuuda, in 1931, an event known as the Second Musha Incident. The novel is structured around the figure of a narrator who rents a house in Qingliu, a village near Puli, previously named Chuanzhongdao (or Kawanakajima in Japanese, the Island Between Rivers), where the few dozen families of Sedeq "survivors" of the 1931 events were eventually resettled, and where the narrator tries to steep himself in the culture of the "moun-

Sebastian Veg is director of the CEFC.

1. For this and further biographical information, see the appendix to the PhD dissertation by Lin Li-ju, Lishi yu jiyi - Wu He de xiaoshuo yanjiu (History and memory - Research on Wu He's fiction), Guoli zhongyang daxue, 2006, pp. 153-165, downloadable from http://thesis.lib.ncu.edu.tw/ETD-db/ETD-search/view_etd?URN= 92131006 (consulted on 27 February 2012). Wu He also explains his choice of penname as inspired simply by the "beauty of image" despite all the literary references it contains.

2. A few remaining problems should be pointed out for correction in possible reprints: a repeated typo in the name of Tokugawa leyasu (p. 148 and note 36); the imprecise rendering of the play on words rubai/naibai: because of its obvious erotic overtones this should probably be rendered as "milk-white"/"breast-white" or something similar; finally an unfortunate error (p. 255) probably due to a missing closing quotation mark in the Chinese original (Wu He, Yu sheng, Taipei, Maitian, 2000, p. 226): according to the grammar, it can only be placed after the words "chucao yishi." 
tain people." As the novel progresses, however, it appears that the historical investigation takes place less by recording memories of the events than through a collage of both discursive and narrative fragments of history. Although Wu He, in an interview with Lin Li-ju, mentions the French nouveau roman as a source of inspiration (the fragmented history of Claude Simon comes to mind), his "novel" is in fact more discourse than narration, sifting various interpretations of history through the critical lens of a reflexive judgment.

The structure of the novel can be understood as referring to a series of narrative models that appear as non-realised possibilities. The first model is the previously mentioned one of a historical investigation: the narrator undertakes to interview several very old Sedeq villagers who remember the era of the massacre. Their testimony gives rise to a historiographical debate, dramatised in a repeated discussion about the correct interpretation of the events: should they be viewed as an anti-colonial uprising with a strong political agenda, or on the contrary, given that both the Sedeq and the Tuuda resorted to the traditional technique of "reaping" heads ( chucao 出草), are they better understood as an ancestral ritual devoid of political meaning, which the Japanese only "chanced" to fall victim to, so to speak? The second structural model, that of a mystic quest, appears in the form of a search for the mysterious valley where Mona Rudao is said to have died (his body was only found three years after the events, in 1933, p. 139/137(3)) and the narrator's spiritual immersion into nature. Finally, a third structuring device is a political and anthropological reflection on the status of aboriginals in Taiwanese society after 1945, and more generally on the presence, within our modern societies, of the Other represented by the heirs of the civilisations we describe as "primitive."

The historical investigation model is the first to appear in the novel; however, while the reader may initially view the novel as one of many literary works bringing to light the memory of traumatic and suppressed events, this understanding proves deceptive. The "Elder," the first eyewitness of the events located by the narrator, retorts that he has "already pretty much covered it" (p. 28/52); the facts of the three successive massacres are well establish in the very first pages of the novel, so that, hardly begun, the narrative seems to have no more revelations to offer. However, it soon appears that the facts are not the most important, because there is no "historical history," only "present history" (pp. 28-29/52). The subject of the novel is hence displaced:

I cannot leave events that are subject to suspicion and discussion become the "past tense" for all time to come, they must be exposed to the contemporary light, toasted in its warmth, so that they may return to the "present tense," the history of the past thus brought back to life becomes a branch of contemporary history [...] the words "the present times faced with the Musha Incident" or "the Musha Incident in present times" must not inspire horror, they are not only the main subject of this novel, they also allow for an appropriate historical viewpoint (p. 71/85)
The point is therefore not so much to establish facts as to evaluate and interpret history; in the light of contemporary norms in particular the act of "reaping" must be discussed in an epistemological framework in which it appears as both a barbaric act and as the essence of the Sedeq civilisation. The last eyewitness who has seen "reaping" take place provides the narrator, who asks what he felt, with an answer that may seem unacceptable: "an incomparable pleasure, inexpressible —-" (p. 165/157). The point is thus not so much to establish what happened in Musha as to return in an almost phenomenological manner to an event that has been obscured by two symmetrical interpretive tendencies: the mythification of Mona Rudao as an anti-colonial hero ${ }^{(4)}$ and the rejection of "reaping" as a barbaric act. In the end, both turn out to be denials of the specific civilisation of the Sedeq.

The interpretive debate about Musha is dramatised in the novel in the form of exchanges between the narrator and two aboriginal intellectuals, Bakan and Danafu, who both oppose the idea that Musha marked a political revolt ("the government has politicised reaping and has made it into an archetype of antiJapanese resistance," p. 23/47) or even a massacre, insofar as "the concept of massacre emanates from civilisation" (p. 22/47). On the contrary, they understand it as a ritual act endowed with its own legitimacy, although it may be problematic for the "contemporary." The narrator attempts to approach the incident in a non-normative manner, first from an anthropological standpoint, considering its evolution from a hunting to a coming-ofage ritual (p. 145/142) and its links with sexual orgies (p. 167/159, p. 257/228). From an aesthetic viewpoint, he underlines its particular form of beauty: "Certainly, at the instant when the head is severed, what exalts the human heart and makes it quiver is precisely this distorted beauty" (p. 201/184). Nonetheless, the narrator cannot go as far as Bakan, who, "considering primitive events from the primitive viewpoint" (p. 204/187), describes the reaping as "civilised resistance against an unjust war" (p. 206/188). Despite his empathy for aboriginal culture, the narrator rejects reaping in the name of free will:

I think with anger and regret of all those who could not escape and were caught up in the collective violence of the era of reaping... The 'contemporary' requests justice for the individual annihilated in the collective [...] all of this is only an ignoble act [...] a carnage carried out against populations unable to defend themselves (p. 255/226).

In his rejection, the narrator establishes a symmetry between the "primitive" ritual and political revolt: the juxtaposition of the

3. The page reference to the French translation discussed here is followed by the page number in the previously referenced original edition.

4. In his seminal book, Michael Berry provides many details to illustrate how Wu He breaks with a long tradition of literary works that make Musha into a pretext to celebrate anti-Japanese nationalism, as well as the guiding role of the Han with respect to the aboriginals. See A History of Pain: Trauma in Modern Chinese Literature and Film, New York, Columbia University Press, 2008.

5. February 28th is also the subject of Wu He's story "Investigation - Narrative" (Diaochao: Xushu), also collected in Sadness. 
two practices suggests an unbroken history of violence, leading a few years later to the events of 28 February 1947 ("2-28") and the White Terror (p. 32/54). ${ }^{(5)}$

In parallel to the historical investigation of Musha and the anthropological discussions about reaping, Wu He introduces a third possible model of narrative structure: the spiritual quest, connected to the pristine nature at the centre of the island where the Sedeq live, among the "trees nurtured on human flesh" (p. 149/144). Right at the beginning, the character Girl - the narrator's neighbour after he moves to the village - introduces herself as Mona Rudao's granddaughter (a claim that seem doubtful in view of the whole novel) and sets out her belief that "by following the rivers upstream, we would end up finding the mysterious valley - the place where her ancestors, one after the other, met with death by jumping off the top of a cliff" (p. 18/43). This aspiration is repeated throughout the novel: the narrator regularly undertakes expeditions to the mountains, where he chances upon an inn in which Mona Rudao's widow once lived. At the very end, the two of them set out together to "go upstream," a trope that also stands for a return in time to the "sources" of history. Although the modern state has attempted to domesticate the mountains by setting up national parks, it is possible to escape from its reach: "Three days are enough to reach the limit where one loses all sense of time" (p. 107/112). Indeed, the final expedition is preceded by a dreamlike prelude in which they visit a Buddhist monastery (of the Sleeping $O x$ ), which suddenly seems to have been unreal when the narrator wakes up the next morning. The mountain peaks therefore seem to belong to a different world, where it is possible to escape from not only the habits of modern civilisation, but also from the space and time that serve as its coordinates. However, when they reach Wuniulan, at the top of the mountain, nothing happens as planned: the narrator and Girl go out for a Western meal and an American movie; the next day, they discover that the beautiful landscapes have been spoiled by construction. It is only in Wushe in the midst of a "serenity alive and joyful like the mist" (p. 276/242) that they feel the possible realisation of a "tiny happiness," but one that holds no key to the events that took place there. In this sense, the spiritual quest is also an illusion. It should be highlighted here that Wu He's engagement with nature and the spiritual dimension of beauty is related to his life in the village. In a 2003 lecture he notes that the natural beauty of the mountains, though stunning, is not unique to Wushe, and relates the particular fascination he felt there for the Musha Incident: "It was very strange: now that this bloody, cruel, and beautiful Musha Incident had passed, its beauty became its most precious legacy." (6) This aesthetic emotion (meigan) remains all the more problematic as the villagers seem oblivious to it, intent only on modernising their houses and developing tourism, as also mentioned in the novel.

These different structural models in fact represent as many aspects of Wu He's central question concerning the place of aboriginal culture at the heart of a modern and developed society such as Taiwan. This perspective throws light on the system of characters constructed by Wu He: Girl, a former prostitute who has returned to the village after a failed marriage and who spends her evenings playing the Chopin nocturnes she learned at the brothel; Old Wolf, the manager of the inn belonging to Mona Rudao's grandson; Mister Strange, the young man who never recovered from a blow on the head in Argentina; and finally, his neighbour Bifu, a political activist defending the territorial rights of aboriginals: "His opposition to the hero cult stems from his own experience inside the aboriginal movements where he has seen 'the demise of many a hero,' he asks for justice for the sacrificed village population just as he denounces unfair elections involving his former comrades" (p. 69/83). All of these characters represent various forms of violence inflicted on aboriginals through their contact with modern society; political action has proven no better than the economic miracle of urban Taiwan at helping them escape from the dynamics of domination of which they are victims.

These characters therefore represent as many survival strategies for a civilisation whose programmed disappearance is not due only to the Japanese coloniser or the repression of the 1930s:

a decade later, different dictators with even greater political and cultural power, even less able to use their brains, further quickened the pace of assimilation [...] the "trend towards assimilation," rather than being interrupted by the Incidents, quickened to Japanification, once the Island Between Rivers had been deliberately proclaimed a model village, countless young people set out to their deaths as "valiant volunteer soldiers" in the jungles of the Southern Seas for the Heavenly Emperor, history presses on, here come the 1970s and 80s, in the brothels of Taipei's Baodou district, as evening falls, the most graceful of those on parade are mostly Atayal girls, what kind of education by assimilation is this? (p. 112/116)

From one colonial regime to another, history, just like Wu He's sentences, inexorably follows its course, hardly held back by an occasional comma, propelled alternately by political and economic dynamics that always converge in the pursuit of what is known as modernity. Blowing the horn of righteous anti-colonialism will therefore not absolve the regimes that followed Japanese domination. Shabo, the veteran who was shell-shocked in the Philippines, resembles the head of the concrete form setters who spent 20 years on the construction sites of Taipei before being laid off in the slowdown of the 1990s. The dynamics of capitalism and development, combined with the boom of tourism and the resilience of an exotic fascination for the uncivilised "other," has completed the marginalisation of aboriginal societies. As a villager at the store remarks: "In less than 30 years, the transformation into entertainment has succeeded in destroying three quarters of the original Sedeq culture, and none

6. Wu He, "Suoyou de dou shi dangdai de - Yu sheng de fanxing sibian" (Everything is contemporary - Reflections on Remains of life), conference at National Tsinghua University, 8 January 2003, http://sites.google.com/site/wujiehmin/home/she-huizheng-zhi-ping-lun/yu-tan-wu-he-qing-hua-suo-you-de-dou-shi-dang-dai-de-yusheng- (consulted on 28 February 2012), p. 5 (unpaginated pdf document). 
of our candidates for office has ever included 'de-entertainmentisation in an election platform" (p. 158/151).

The narrator underlines by contrast "how much more advanced the primitive is than the civilised" (p. 118/121), thus replacing the meaning of his quest within the larger context of the search for other "realities" than the modern cities of the west coast: "As I have verified myself, it is possible, at the heart of the fin de siècle civilisation of this tiny island, to 'live in the midst of the primitive experience'"' (p. 144/140-141). The lengthy developments on "natural" Atayal sexuality (p. 167/159, 176/165), which might appear as one more example of an exotic fascination for the "primitive other" on the part of the narrator, also serve to underscore the Atayal's capacity to resist coercion, which has universal validity. It is precisely this universal dimension that is inherent in the word "survival" or "survivors," yu sheng 餘生, which the translators might also have translated as "the remains of life" (as Michael Berry does in his essay) or "the remaining life," and which is not limited to the idea of "the time we have left," as claimed in the preface. Strolling around the "monument to survival" in Mahepo, the narrator wonders: "It was not chance that brought me to the Island Between Rivers, I settled here only because of the word 'survival,' I wanted to confront the reality behind the words 'surviving after the catastrophe'"' (p. 202/185). This catastrophe goes far deeper than one historical event, highlighting the ironic fact that the "barbarians" were in fact the last people to resist the barbaric advance of civilisation and the forms of repression and violence it has repeatedly produced throughout the twentieth century. The narrator's decision to leave the cities is therefore also an expression of the "revolt against existence" (p. 258/229) that models itself on the survivors: "at forty-five I have begun the first year of my life, my long survival" (p. 260/230).

Hence, there is no need, in order to take the viewpoint of the victims or of those excluded by the main narratives, to romanticise history and recreate heroes. This is the path taken by the "nativist" presidents Lee Teng-hui and Chen Shui-bian, who respectively erected a statue of Mona in Wushe in 1997 and minted 20-yuan coins with Mona's effigy in 2001. (7) In the 2003 conference, Wu He expresses deep consternation at the removal of the original monument to survival to make way for the statue, as well as his disappointment that the villagers themselves should be interested only in developing tourism without any feeling for the authenticity of the place, and concludes by saying that his book can never make up for the loss of the original plaque. ${ }^{(8)}$ There is no call, either, to turn Musha into a new "national epic" as in Wei Te-sheng's effect-studded two-hour film Seedeq Bale, which scored a great box office hit in Taiwan in 2011. The narrator of the novel does not relinquish his ethical standpoint, rejecting any form of "reaping" as a "collective will and ritual" in the name of the contemporary endorsement of "the free-will of existence" (p. 282/247). This is one of the aspects of what Wu He calls "non-participant observation" (fei canyu shi de guancha), ${ }^{(9)}$ which sets literature apart from anthropology, even though Yu Sheng is described as a "fieldworknovel."

What matters, in the end, is not the revelation of a historical truth, establishing who is right and who is wrong, any more than a mystical revelation, locating in nature or "primitive" cultures a "lost truth" about the world and mankind. What matters is the "overflow of life" that can be found at every moment of existence. The narrator writes: "Having settled in the Island Between Rivers and having confronted the Musha Incidents, I consider all these realities as part of the course of my own existence, not its meaning, only its 'course" (p. 133/133). In a pattern not unlike Gao Xingjian's Soul Mountain, it is the path itself rather than its destination, and life itself rather than its goal, that produces meaning. All living realities may produce such an "excess" of meaning. Resisting the logic of modernity and civilisation also means remaining open to the many possibilities of life. In this way, the novel closes with an encounter between the narrator and an old Sedeq, married to a woman from the enemy Tuuda tribe. After many long years of mutual distrust of a marriage arranged for political reasons, they finally fall in love in their old age, after having visited their children in the modern city of Taichung: "We don't let the past spoil the present or the present spoil the future, and this is how we should survive... in bed and without thinking too much about anything" (p. 287/250).

7. See Michael Berry, A History of Pain, op. cit., p. 93.

8. Wu He, "Suoyou de dou shi dangdai de," art. cit., p. 6. At the same time, however, he believes that it should be for the aboriginals only to decide, and that an outsider such as himself has no right to intervene.

9. Ibid., p. 5; see also the introduction by Wu Chieh-min, "Liangzhong shuo gushi de fangshi: Liangtao guixin de faze" (Two ways of telling a story, two disciplinary methods), ibid., p. $1 \mathrm{ff}$. The two "disciplines" referred to are literature and anthropology. 